\title{
Anesthetic Considerations in Hepatectomies under Hepatic Vascular Control
}

\author{
Aliki Tympa, ${ }^{1}$ Kassiani Theodoraki, ${ }^{1}$ Athanassia Tsaroucha, ${ }^{1}$ Nikolaos Arkadopoulos, ${ }^{2}$ \\ Ioannis Vassiliou, ${ }^{3}$ and Vassilios Smyrniotis ${ }^{2}$ \\ ${ }^{1}$ First Department of Anesthesiology, School of Medicine, University of Athens, Aretaieion Hospital, 76 Vassilisis Sofias Avenue, \\ 11528 Athens, Greece \\ ${ }^{2}$ Fourth Department of Surgery, School of Medicine, University of Athens, Attikon Hospital, 1 Rimini Street, 12410 Chaidari, Greece \\ ${ }^{3}$ Second Department of Surgery, School of Medicine, University of Athens, Aretaieion Hospital, 76 Vassilisis Sofias Avenue, \\ 11528 Athens, Greece
}

Correspondence should be addressed to Aliki Tympa, tympaaliki@yahoo.gr

Received 9 January 2012; Revised 6 March 2012; Accepted 21 March 2012

Academic Editor: Pierre-Alain Clavien

Copyright ( 2012 Aliki Tympa et al. This is an open access article distributed under the Creative Commons Attribution License, which permits unrestricted use, distribution, and reproduction in any medium, provided the original work is properly cited.

Background. Hazards of liver surgery have been attenuated by the evolution in methods of hepatic vascular control and the anesthetic management. In this paper, the anesthetic considerations during hepatic vascular occlusion techniques were reviewed. Methods. A Medline literature search using the terms "anesthetic," "anesthesia," "liver," "hepatectomy," "inflow," "outflow occlusion," "Pringle," "hemodynamic," "air embolism," "blood loss," "transfusion," "ischemia-reperfusion," "preconditioning," was performed. Results. Task-orientated anesthetic management, according to the performed method of hepatic vascular occlusion, ameliorates the surgical outcome and improves the morbidity and mortality rates, following liver surgery. Conclusions. Hepatic vascular occlusion techniques share common anesthetic considerations in terms of preoperative assessment, monitoring, induction, and maintenance of anesthesia. On the other hand, the hemodynamic management, the prevention of vascular air embolism, blood transfusion, and liver injury are plausible when the anesthetic plan is scheduled according to the method of hepatic vascular occlusion performed.

\section{Introduction}

Hepatectomy is one of the therapies available for benign and malignant liver disease. Although liver resections have been associated with high mortality and morbidity rates, recent advances in anesthetic and surgical management have significantly reduced the operative risk. The techniques of vascular control during hepatectomy are highly demanding and should be performed under special anesthetic considerations.

Hepatic vascular control methods can be categorized as those involving occlusion of liver inflow and those involving occlusion of both liver inflow and outflow. They can be summarized as following.
(1) Inflow vascular occlusion.

(A) Hepatic pedicle occlusion:

(a) Continuous Pringle maneuver (CPM),

(b) intermittent Pringle maneuver (IPM).

(B) Selective inflow occlusion.

(2) Inflow and outflow vascular exclusion

(A) Total hepatic vascular exclusion (THVE),

(B) inflow occlusion with extraparenchymal control of the major hepatic veins: with selective hepatic vascular exclusion (SHVE). 
When performing these techniques, the conduct of anesthesia should take into account hemodynamic management, risks of vascular air embolism, ischemia reperfusion liver injury, intraoperative blood loss, and the need for transfusion, factors which usually complicate hepatic vascular control methods. Special attention should also be paid to the preoperative assessment and induction of anesthesia, as patients undergoing liver resection usually have a compromised health status. Careful selection of the anesthetic drugs can minimize the effects of hepatic blood flow decrease induced by the surgical technique adopted.

\section{Methods}

A comprehensive literature search was performed. Our objective was to identify the anesthetic considerations in techniques of hepatic vascular control methods. Articles were selected by a Medline literature search, according to the following criteria.

(1) All prospective randomized studies were thoroughly evaluated and presented, as they are the most important source of information on the outcomes of surgical and anesthetic manipulations.

(2) Large retrospective studies were also included. Few case reports and smaller studies are mentioned, given the fact that they highlight special anesthetic aspects.

\section{Results}

3.1. Preoperative Assessment. Healthy patients undergo a routine preoperative assessment including a full blood count and a standard biochemical and coagulation test.

Preexisting hepatic impairment is a risk factor, even for nonhepatic surgery, with higher blood transfusion requirements, a longer hospital stay, a higher number of complications, and increased mortality rates of $16.3 \%$ in cirrhotic patients as compared to $3.5 \%$ in controls [1]. Estimating the health status of patients presenting for hepatectomy is quite challenging: coagulopathy, volume and electrolyte disturbances, viral infections (Hep C), hepatorenal [2-4] and hepatopulmonary [3] syndrome, portopulmonary hypertension, and low cardiovascular reserve capacity can occur in patients with chronic liver disease.

The identification of patients at risk to develop postoperative hepatic or renal failure is important and, ideally, involves many related disciplines such as surgery, anesthesia, and intensive care. Although vascular occlusion techniques have minimized hepatic bleeding, the risk for postoperative liver and/or renal failure remains high for patients of advanced age and those with steatosis and cirrhosis, on preoperative chemotherapy and with small remnant liver volumes [5]. Slankamenac et al. [6] have developed and validated a prediction score for postoperative acute liver failure following liver resection based on the preoperative parameters of cardiovascular disease, chronic liver failure, diabetes, and ALT levels, which seems to be an easily applicable and attractive tool in clinical practice.
Vascular control techniques during hepatectomy require optimization of the cardiac and pulmonary function [7]. Hepatic ischemia and reperfusion on subsequent liver dysfunction is associated with unexpected responses to surgical stress [7-9] and poor prognosis [10]. Patients with endstage liver disease have a characteristic hemodynamic profile: increased cardiac output with blunted response to painful stimuli, splanchnic vasodilatation and central hypovolemia. As a result, silent moderate-to-severe coronary artery disease cannot be easily recognized. Currently, there are no specific guidelines for the identification of coronary artery disease in patients with advanced liver disease $[11,12]$. Preoperative invasive assessment of preexisting cardiovascular dysfunction is indicated only for high risk patients, provided that any coagulopathy is corrected [11]. In the noninvasive assessment of coronary artery disease in patients with cirrhosis, dobutamine stress echocardiography has failed as a screening tool [12]. Furthermore, beta blockade discontinuation in order to permit adequate cardiac function assessment may be hazardous in patients with advanced liver disease [12]. Beta blockers reduce portal hypertension, decrease cardiac workload, and their use seems to be beneficial to both the liver and the heart in the setting of hepatectomy.

In general, the preoperative assessment needs to be adapted to the individual patient to minimize the perioperative liver insults of hepatic vascular control.

3.2. Induction and Maintenance of Anesthesia. Liver resections are usually performed under general anesthesia with tracheal intubation and controlled ventilation. Patients with ascites undergo rapid sequence induction [13]. Cis-atracurium is the nondepolarizing muscle relaxant of choice in patients with liver disease as it is hydrolyzed by Hoffman elimination. Moreover, it is haemodynamically stable due to its scarce release of histamine [14]. Atracurium can provide stable neuromuscular blockade, as its requirements remained unchanged during exclusion of the liver from the circulation [15].

An intravenous hypnotic is used for induction and a halogenated volatile agent in air-oxygen mixture is used for maintenance [16]. Hepatic vascular control techniques depress cardiovascular function in addition to the depression caused by general anesthesia. Careful selection of the volatile agent is required. Most commonly used volatile anesthetics for maintenance are isoflurane and sevoflurane. Isoflurane has mild cardiodepressive effects but maintains hepatic oxygen supply, due to vasodilatation in the hepatic artery and portal vein [17]. Both isoflurane and sevoflurane upregulate heme-oxygenase-1, release iron and carbon monoxide, and thus decrease portal vascular resistance in rats [18]. In humans, sevoflurane decreases portal vein blood flow but increases hepatic artery blood flow [19]. In addition, BeckSchimmer et al., in a randomized controlled trial on patients undergoing liver surgery [20], showed that ischemic preconditioning with sevoflurane before inflow occlusion limited postoperative liver injury, even in patients with steatosis. Although various inhalational anesthetics are used in liver surgery, no optimal anesthetic technique has been established for the maintenance of anesthesia. Desflurane appears 
TABLE 1: Hemodynamic changes on clinical series of hepatectomies induced by hepatic vascular occlusion techniques.

\begin{tabular}{|c|c|c|c|c|}
\hline & \multirow{2}{*}{ Technique } & \multicolumn{3}{|c|}{ Haemodynamic changes } \\
\hline & & Heart rate & Mean arterial blood pressure & Cardiac index \\
\hline \multirow{8}{*}{ Inflow and outflow occlusion } & THVE* & & & \\
\hline & Redai et al. ${ }^{\mathrm{a}}[16]$ & $\uparrow 25 \%$ & $\downarrow 17,64 \%$ & $\downarrow 50 \%$ \\
\hline & Smyrniotis et al. ${ }^{\mathrm{a}}$ [123] & $\uparrow 21 \%$ & $\downarrow 23 \%$ & $\downarrow 50 \%$ \\
\hline & Figueras et al. ${ }^{\mathrm{a}}[124]$ & $\uparrow 18,75 \%$ & $\downarrow 20,48 \%$ & $\downarrow 60 \%$ \\
\hline & Smyrniotis et al. [54] & $\uparrow 29 \%$ & $\uparrow 22 \%$ & $\downarrow 50 \%$ \\
\hline & $\mathrm{SHVE}^{* *}$ & & & \\
\hline & Figueras et al. ${ }^{\mathrm{a}}[124]$ & $\uparrow 2,46 \%$ & $\uparrow 3,79 \%$ & N/A \\
\hline & Smyrniotis et al. [54] & $\uparrow 5 \%$ & $\uparrow 5,55 \%$ & $\downarrow 10 \%$ \\
\hline \multirow{4}{*}{ Inflow occlusion } & Pringle & & & \\
\hline & Redai et al. ${ }^{a}[16]$ & $\uparrow 6.25 \%$ & $\uparrow 15 \%$ & $\downarrow 10 \%$ \\
\hline & Smyrniotis et al. ${ }^{a}[123]$ & $\uparrow 12 \%$ & $\uparrow 16 \%$ & $\downarrow 10 \%$ \\
\hline & Figueras et al. ${ }^{\mathrm{a}}[124]$ & $\uparrow 8.83 \%$ & $\uparrow 13.85 \%$ & N/A \\
\hline
\end{tabular}

${ }^{a}$ Values expressing \% change of heart rate, mean arterial blood pressure, and cardiac index during clamping and uclamping of hepatic vessels.

*THVE: total hepatic vascular exclusion.

**SHVE: selective hepatic vascular exclusion.

$\uparrow$ : increase.

$\downarrow$ : reduction.

to have no greater liver toxicity than currently used volatile anesthetic agents [21]. Additionally, desflurane undergoes only minor biodegradation (it is metabolized at a ratio of $0.02 \%$ ) and in fact it may cause less hepatocellular damage due to its reduced metabolism [21]. Ko et al. [22], comparing the effects of desflurane and sevoflurane on hepatic and renal functions after right hepatectomy in living donors reported better postoperative hepatic and renal function tests with desflurane as compared to sevoflurane at equivalent doses of $1 \mathrm{MAC}$ without, however, being able to validate the clinical importance of their study. Arslan et al. [23] comparing the effects of anesthesia with desflurane and enflurane on liver function, showed that during anesthesia with desflurane, liver function was well preserved; glutathione-S-transferase and aspartate aminotransferase levels were significantly lower in the desflurane group. On the other hand, Laviolle et al. [24] suggested that propofol has an early protective effect against hepatic injury compared with desflurane after partial hepatectomy under inflow occlusion.

It is now generally accepted that anesthesia reduces hepatic blood flow. However, few studies on the effects of general anesthesia during hepatectomies under vascular control techniques are available in patients with significant comorbidities.

\subsection{Hemodynamic Management}

3.3.1. Inflow Vascular Occlusion. CPM, IPM, and selective inflow occlusion share common hemodynamic management. Portal triad clamping increases systematic vascular resistance by up to $40 \%$ and reduces cardiac output by $10 \%$. Mean arterial pressure increases about 15\% (Table 1). Following unclamping, hemodynamic parameters gradually return to baseline values [25-28]. However, the systemic circulation in patients with cirrhosis is hyperdynamic and dysfunctional, with increased heart rate and cardiac output, decreased systemic vascular resistance, and low or normal arterial blood pressure. Thus, maintaining adequate organ perfusion may be difficult to achieve and preoperative optimization of the patient is required.

The anesthetic management is dictated by the surgical approach and the patient's health status. For healthy patients, routine monitoring is used. Monitoring can even be limited to just peripheral vein catheters [29]. Invasive monitoring provided by a central venous line or pulmonary catheterization is reserved for patients with poor cardiovascular status or when prolonged vascular occlusions are performed.

A low CVP (between 2 and $5 \mathrm{mmHg}$ ), while aiming at euvolemia, reduces blood loss during liver surgery and improves survival $[30,31]$. A low CVP can be achieved by limitation of intravenous fluids administration pre- and intraoperatively. Maintenance fluids and crystalloids to stabilize blood pressure $>90 \mathrm{mmHg}$ and ensure diuresis of at least $0.5 \mathrm{~mL} / \mathrm{kg} / \mathrm{h}$ can be used safely with minor hemodynamic disturbance [32]. If fluid restriction is ineffective to keep a low CVP, vasoactive agents are used. Nitroglycerin reduces CVP to the desired level during the resection phase or when excessive oozing is observed from the resected surface $[13,16]$. Intravenous morphine has also been used for its hypotensive effect.

CPM with a CVP of $5 \mathrm{mmHg}$ or less is associated with minor blood loss and a shorter hospital stay [33]. IPM may result in fluctuations of systemic blood pressure. If, however, it is applied under a low CVP during transection, blood loss and hemodynamic changes are minimal [34-37]. In an experimental animal study, Sivelestat, a neutrophil elastase inhibitor, reduced hepatic injury and stabilized hemodynamics after ischemia-reperfusion following IPM [38]. 
The advantages of a low CVP must be weighed against inadequate perfusion of the vital organs and loss of volemic reserve in case of bleeding and/or air embolism. A $15^{\circ}$ Trendelenburg position protects against air embolism. Melendez et al. [34] support that in low CVP anesthesia during liver resection, the incidence of perioperative renal failure does not increase significantly.

\subsubsection{Inflow and Outflow Vascular Occlusion}

(1) Total Hepatic Vascular Exclusion (THVE). In THVE, rapid hemodynamic changes (Table 1) are frequent due to surgical events such as caval clamping, sudden blood loss, and hepatic reperfusion. Cross-clamping of the inferior vena cava and portal vein result in a 40-60\% reduction of venous return and cardiac output, with a compensatory $80 \%$ increase in systemic vascular resistance and a 50\% increase in heart rate. Although systemic vascular resistance and heart rate increase, the cardiac index is reduced by half, secondary to a preload reduction. Unclamping is followed by an increase in cardiac index and a significant reduction in systemic vascular resistance [39].

The anesthetist should take prompt steps to manage the preload reduction and the sudden decrease in cardiac output evoked by the inferior vena cava and portal vein clamping. Intraoperative monitoring includes ECG, pulse oximetry, $\mathrm{ETCO}_{2}$ tension, invasive blood pressure monitoring through an arterial line, and CVP monitoring through a large bore central venous line. Patients with pulmonary hypertension require pulmonary artery catheterization. In addition, the presence of a pulmonary artery catheter allows the tailored administration of vasopressors in case of massive hemorrhage due to vena cava injury. The Vigileo, an uncalibrated arterial pulse contour cardiac output monitoring system, has been proved to be unreliable in cirrhotic patients with hyperdynamic circulation undergoing major liver surgery [40].

Before THVE, colloids can be administered to prevent the abrupt decrease in cardiac output. Colloids, beyond correcting volume deficits [33], improve splanchnic circulation, displace fluid into the blood compartment, and reduce bowel edema. Blood pressure and circulatory support is achieved by aiming at a CVP of at least $14 \mathrm{mmHg}$ [16]. Vasopressin or norepinephrine are administered if volume loading is inadequate to maintain blood pressure following clamping of the vena cava [7].

There is no standard approach to the use of vasoactive agents in THVE. Most studies have mainly been performed in septic patients or in animal models. Vasoactive agents should be used carefully, as they improve cardiac output at the expense of microcirculatory blood flow. During vascular isolation of the liver in eight pigs, norepinephrine infusion $(0.7 \mu \mathrm{g} / \mathrm{kg} / \mathrm{min})$ decreased hepatic vascular capacitance by activation [41]. In a recent study in septic patients, Krejci et al. [42] showed that norepinephrine increased systemic blood flow but reduced microcirculatory blood flow on liver's surface.

Vasopressin on the other hand, is known to rapidly restore blood pressure during septic shock. However, in an experimental study [43], vasopressin proved to be inferior to norepinephrine in terms of improving hepatosplanchnic blood flow. The response to both norepinephrine and vasopressin is blunted in patients with cirrhosis [44, 45].

Preventing renal impairment is another important consideration for the anesthesiologist. Renal autoregulation ceases below a renal perfusion pressure of 70 to $75 \mathrm{mmHg}$, below which, flow becomes pressure dependent. Perioperative fluid shifts, intravascular hypovolemia, and sympathetic activation during THVE result in a reduction of renal blood flow. Mannitol, furosemide, and "low dose dopamine" have been used with the aim of preventing intraoperative renal injury without evidence of substantial benefit [46]. Fenoldopam had beneficial effects [47] on postoperative creatinine levels and creatinine clearance of critically ill patients [48]. Recently, terlipressin along with volume expansion have been shown to improve renal function, without, however, improving survival [49].

Hemodynamic intolerance to THVE or ischemia under THVE exceeding 30 or 60 minutes, require venovenous bypass $[50,51]$. THVE should be limited to selected cases, as hemodynamic intolerance has been observed in 10-20\% of patients, as well as increased morbidity and hospital stays (Table 2).

(2) Selective Hepatic Vascular Exclusion (SHVE). SHVE is a flexible technique that can be applied in a continuous or intermittent manner. Should accidental tears of major hepatic veins occur, rapid conversion to THVE must be undertaken. The literature suggests that many institutions favor SHVE as one of the standard methods of vascular control because it provides a bloodless surgical field and it is tolerated by most patients. No special anesthetic considerations regarding the hemodynamic management of SHVE are referred, as this method diminishes blood pressure and heart rate fluctuations during liver resection (Table 1).

In a cohort study [52] among 246 patients, hemodynamic tolerance to SHVE was excellent with only a slight increase in systemic and pulmonary resistance during clamping. No deaths were reported and the mean hospital stay was 9.6 days.

SHVE is the method of choice in cases when CVP cannot be lowered (i.e., right heart failure, poor cardiovascular status) [53-56]. In a retrospective study on 102 patients, SHVE was shown to be unaffected by CVP levels and the authors concluded that it should be used whenever CVP remains high despite adequate anesthetic management [57]. Although the performance of SHVE requires significant surgical expertise, it is tolerated by most patients and has a hemodynamic profile similar to that of CPM [53, 54]. Furthermore, it controls backflow bleeding of the hepatic veins. In a large clinical study [58], SHVE proved to be more effective than CPM in controlling intraoperative bleeding, preventing blood loss, and reducing postoperative complications and mortality rates (Table 2 ). Combined SHVE and perioperative fluid restriction has also been suggested as a liver and renal protective procedure in partial hepatectomy. Moug et al. [59] demonstrated that active preoperative dehydration of the 
TABLE 2: Clinical series of hepatectomies performed under vascular occlusion techniques.

\begin{tabular}{|c|c|c|c|c|c|c|}
\hline Technique-study & $\begin{array}{l}\text { No. of } \\
\text { patients }\end{array}$ & Type of hepatectomy ${ }^{a}$ & Clamp time (min) & Morbidity/mortality (\%) & Transfusions (\%) & $\begin{array}{c}\mathrm{CVP} \\
(\mathrm{mmHg})\end{array}$ \\
\hline \multicolumn{7}{|l|}{ I.Pb } \\
\hline Torzilli et al. [36] & 329 & Major 71\% & 69 & $26 / 0$ & 3.9 & N/A \\
\hline Nuzzo et al. [125] & 120 & Major 38\% & 39 & N/A & 60 & $<5$ \\
\hline Omar Giovanardi et al. [126] & 72 & Major 81\% & N/A & $24 / 7$ & 57 & N/A \\
\hline \multicolumn{7}{|l|}{ THVE $^{c}$} \\
\hline Smyrniotis et al. [54] & 18 & Major & 32 & $33 / 0$ & 30 & N/A \\
\hline Figueras et al. [124] & 39 & N/A & 41 & N/A & 4 & 6.4 \\
\hline \multicolumn{7}{|l|}{ SHVE $^{d}$} \\
\hline Smyrniotis et al. [54] & 20 & Major & 38 & $25 / 0$ & 15 & $<5$ \\
\hline Zhou et al. [58] & 125 & N/A & 21.7 & $39.2 / 0$ & 32 & 4.4 \\
\hline Fu et al. [127] & 246 & Major & N/A & $24.8 / 0$ & 24 & $2-5$ \\
\hline Figueras et al. [124] & 41 & N/A & 47 & N/A & 6 & 7.2 \\
\hline \multicolumn{7}{|l|}{ Pringle-IPM ${ }^{e}$} \\
\hline Wang et al. [98] & 114 & N/A & N/A & N/A & 13.1 & $5-10$ \\
\hline Zhou et al. [58] & 110 & N/A & 22.5 & $51.8 / 1.8$ & 80.9 & 4.6 \\
\hline Ishizaki et al. [128] & 380 & Major 39.4\% & 62 & $23.9 / 0$ & 34 & N/A \\
\hline
\end{tabular}

aajor hepatectomy is defined as resection of more than two segments according to Couinaud's classification.

${ }^{b}$ I.P: ischemic preconditioning.

'THVE: total hepatic vascular exclusion.

${ }^{\mathrm{d} S H V E}$ : selective hepatic vascular exclusion.

eIPM: intermittent pringle maneuver.

patient, low CVP anesthesia and SHVE resulted in minimal blood loss, low morbidity, and zero mortality in patients undergoing partial liver resection.

In conclusion, SHVE which is not associated with cardiorespiratory and hemodynamic alterations is well tolerated by the majority of patients and requires shorter hospitalization times [54].

3.4. Vascular Air Embolism. Although the relative risk of air embolism in hepatic surgery is low $(<5 \%)$ [60], several cases have been reported during liver vascular control techniques. Factors predisposing to vascular air embolism during liver resections include: (a) surgical technique, (b) size and place of the tumor, (c) blood loss, and (d) low CVP anesthesia.

Clinical signs of vascular air embolism during anesthesia with respiratory monitoring are: a decrease in end-tidal carbon dioxide and decreases in both arterial oxygen saturation $\left(\mathrm{SaO}_{2}\right)$ and tension $\left(\mathrm{PO}_{2}\right)$, along with hypercapnia. From the cardiovascular system monitoring, tachyarrhythmias, electromechanical dissociation, pulseless electrical activity as well as ST-T changes can be noted. Major hemodynamic manifestations such as sudden hypotension may occur before hypoxemia becomes present.

When performing techniques of inflow vascular occlusion (CPM, IPM, selective inflow occlusion), air embolism may be observed during parenchymal transection under low CVP anesthesia or during reperfusion, due to mobilization of air bubbles trapped in opened veins. Resection of large tumors situated in the right lobe [61], close to the inferior vena cava or the cavohepatic junction, put the patient at risk of venous air embolism. Those tumors should therefore be resected under THVE or SHVE if possible. Recent clinical trials assessing the efficacy of SHVE and Pringle maneuver in preventing vascular air embolism showed that embolism occurred in three out of 2100 patients or in one out of 29 patients of the Pringle group, following massive blood loss during tumor resection. Air embolism did not occur in any case of the SHVE group [62-64].

Massive bleeding $(>5000 \mathrm{~mL})$ and subsequent air embolism can even result in intraoperative death in patients undergoing major liver resections [65]. The morbidity and mortality of air embolism depend on the volume and rate of air accumulation [66]. From case reports of accidental intravascular delivery of air, the adult lethal volume has been described as between 200 and $300 \mathrm{~mL}$ or $3-5 \mathrm{~mL} / \mathrm{kg}[67,68]$. Low CVP further enhances the negative pressure gradient at the surgical field compared to the right atrium and increases the possibility of air embolism.

Currently, the most sensitive monitoring devices for vascular air embolism are transesophageal echocardiography and precordial Doppler ultrasonography, detecting as little as $0.02 \mathrm{~mL} / \mathrm{kg}$ and $0.05 \mathrm{~mL} / \mathrm{kg}$ of air, respectively [69-71].

The consequences of air embolism can be minimized by placing the patient in a 15 degree Trendelenburg position [72-74]. However, recent literature has questioned the efficacy of Trendelenburg position on improving hemodynamics [75]. Furthermore, Moulton et al. [75] in a small study among ten patients, showed that patient positioning alone during liver surgery does not affect the risk of venous air embolism. Thus, the beneficial effects of low CVP in 
liver resections must be carefully weighed against adequate hydration and volume status optimization.

Vascular air embolism is a potentially hazardous complication. Additionally, cirrhotic patients undergoing hepatectomy have pulmonary abnormalities including intrapulmonary shunting, pulmonary vascular dilatation, and arteriovenous communications. In these patients, air can pass into the systemic circulation (paradoxical air embolism), even if cardiac abnormalities (patent foramen ovale) are not present, evoking fatal consequences [76].

Recent literature suggests that SHVE prevents vascular air embolism and provides operative tolerance. However, recognizing the risk for vascular air embolism and planning the appropriate level of monitoring and treatment is the key to patient safety.

3.5. Blood Loss and Transfusion. Liver resections may result in significant blood loss and subsequent transfusion of RBC (red blood cells) in about $25 \%-30 \%$ of patients [77]. The two main sources of bleeding during a liver resection are (a) the inflow system (hepatic artery and portal vein) and (b) the outflow system (backflow bleeding from the hepatic veins). Bleeding may also occur during liver mobilization, hepatic transection, and dissection of biliary structures.

Blood loss has been linked to morbidity and mortality since 1989 [8], whereas RBC transfusions are associated with multiple disadvantages, risks, and side effects. Furthermore, operative blood loss independently predicts recurrence and survival after resection of hepatocellular carcinomas [78]. Operative mortality in patients refusing blood transfusions was $7.1 \%$ for patients with hemoglobin levels $>10 \mathrm{~g} / \mathrm{dL}$ and $61.5 \%$ for patients with hemoglobin levels $<6 \mathrm{~g} / \mathrm{dL}[79,80]$.

The refinement of inflow and outflow occlusive techniques as well as the appropriate anesthetic management has reduced intraoperative bleeding and the need for blood transfusions. The surgical approach to hepatic resection is of major importance in preventing blood loss. Study of the literature reveals the following results regarding bleeding with different vascular occlusion techniques: Pringle maneuver has been shown to be effective in reducing blood loss during parenchyma transection [81]. Portal triad clamping is associated with less bleeding compared with no clamping [82]. In procedures of liver ischemia time $<$ one hour, CPM is equal to IPM. Belghiti et al. [9], in a prospective study of IPM versus CPM, found no difference in total blood loss or the volume of blood transfused between the two groups, despite higher blood loss during parenchyma transection. Man et al., in two prospective studies of IPM versus no use of vascular control at all, showed lower total blood loss and fewer transfusions in the IPM group [83-85]. Hemihepatic vascular clamping was shown superior to IPM and to no application of vascular control, with reduced both blood loss and transfusion requirements [86]. SHVE provides a bloodless surgical field similar to THVE, but is better tolerated by patients. Many authors favor SHVE as one of the standard methods of vascular control, as it substantially prevents massive blood loss and diminishes transfusion needs.
From an anesthetic standpoint, a low CVP level plays an important role in reducing intraoperative blood loss and transfusion rates $[30,57,87]$. Maintaining a CVP $<5 \mathrm{mmHg}$ by volume restriction and intravenous infusion of nitroglycerine and a systolic blood pressure above $90 \mathrm{mmHg}$ by intravenous infusion of dopamine $(4-6 \mu \mathrm{g} / \mathrm{kg})$ has dramatically reduced bleeding and transfusion requirements [88]. The anesthetist should also provide normothermic conditions to the patient undergoing liver resection, because hypothermia reduces blood coagulation, especially platelet function, and increases intraoperative blood loss.

Alternative methods of diminishing blood loss have been investigated. Of the pharmacological methods, desmopressin, although used in treating hemophilia, was not effective in reducing blood loss and transfusion needs in patients undergoing liver resection. In a randomized clinical trial, the use of recombinant factor VIIa in major liver resections failed to reduce the number of units transfused [89]. A significant reduction in blood transfusion needs in liver resections has been shown with the use of aprotinin. Aprotinin was found to reduce intraoperative blood loss by $25 \%$ and transfusion requirements by $50 \%$ [81]. Redai et al. [16] used half dose aprotinin $\left(10^{6} \mathrm{KIU}\right.$ followed by $2.5 \times$ $10^{5} \mathrm{KIU} /$ hour infusion) during hepatic transplantation in patients who have a significant coagulopathy or portal hypertension and in those who had previous abdominal surgery. However, Lentschner et al. [90] cautioned against the routine use of aprotinin due to the incidence of life threatening allergic reactions, thrombotic potential, and renal failure. Currently, there is no scientific support for the routine use of aprotinin in patients undergoing partial hepatectomy, whereas its efficacy in liver transplantation is well established [91]. Tranexamic acid has also been shown to reduce blood requirements in liver resection surgery but safety concerns have been raised and require further investigation [92, 93]. In the future, two artificial oxygen carriers (hemoglobin solutions and perfluorocarbons) may become essential in reducing the need for allogeneic RBC transfusions [94-96]. Artificial oxygen carriers improve $\mathrm{O}_{2}$ delivery and tissue oxygenation as well as the function of organs with marginal $\mathrm{O}_{2}$ supply. More studies examining their efficacy in ischemic liver during hepatectomy need to be performed.

Undoubtedly, the improvement of vascular control techniques during hepatectomy has permitted an aggressive approach for liver resections with low mortality rates $(4 \%)$ [52]. In addition, anesthesia orientated towards an almost transfusion free setting has also improved mortality and morbidity following liver surgery. To this direction, Pulitanò et al. [97] proposed a score predicting blood requirements in liver surgery. A transfusion risk score, including variables of: (a) preoperative hemoglobin concentrations below $12.5 \mathrm{~g} / \mathrm{dL}$, (b) largest tumor more than $4 \mathrm{~cm}$, (c) need for exposure of the vena cava, $(\mathrm{d})$ need for an associate procedure, and (e) cirrhosis, accurately predicted the likelihood of blood transfusions in liver resections.

Recently, Cescon et al. [52], in a retrospective review assessing the outcome of 1500 consecutive patients who underwent hepatic resection, estimated overall mortality and morbidity at $3 \%$ and $22.5 \%$, respectively. Their multivariate 
analysis revealed that blood transfusions, primary liver tumors, and additional procedures were associated with an increased risk of postoperative complications, whereas blood transfusions, cirrhosis, biliary malignancies, and extended hepatectomy were associated with an increased risk of postoperative mortality. Wang et al. [98], evaluating the longterm outcomes of liver resection for hepatocellular carcinoma, estimated that $86.9 \%$ of the patients did not require perioperative blood transfusion and that Pringle maneuver and RBC transfusions are independent prognostic factors influencing survival.

Blood transfusions are well known to carry the risk of transmitted infections, acute or delayed reactions and "wrong blood" incidents. In liver resections, blood transfusions are associated with suppression of the immune system. There is strong evidence that blood transfusions have an impact on tumor recurrence for patients with early stages of hepatocellular carcinoma. However, no such effect could be demonstrated for patients undergoing partial liver resection for late stages of hepatocellular carcinoma, colorectal metastasis, or cholangiocarcinoma [99]. Transfusion evoked immunosuppression is also responsible for TRALI (transfusion-related acute lung injury). Dyspnea, hypotension, fever, and bilateral noncardiogenic pulmonary edema, present within $6 \mathrm{~h}$ of transfusion and complicate the postoperative outcome of patients following major liver surgery [100]. Patients with chronic liver disease have the greatest risk of developing TRALI, in comparison to other populations [101, 102]. Although all blood products can lead to this life-threatening situation, plasma-containing products were responsible for the majority of cases in patients undergoing liver transplantation [101]. Recent studies suggest that TRALI fatalities followed plasma transfusion components were linked to multiparous female donors with leukocyte antibodies [103, 104]. Therefore, the establishment of new strategies in blood donation excluding multiparous women as donors, as potential carriers of TRALI-inducing antibodies, is expected to eliminate this entity.

In conclusion, given the influence of blood loss and transfusions on the surgical outcome, techniques of liver vascular control and anesthetic management should be adjusted to the individual patient. The tumor location, the underlying liver disease and the patient's cardiovascular status should therefore be taken into account, in order to minimize blood loss and transfusion requirements.

3.6. Ischemia-Reperfusion Injury and Preconditioning. Ischemia/reperfusion ( $I / R)$ injury is a serious complication of liver surgery, especially after extended hepatectomies [105]. It causes a local and systemic inflammation response and its clinical manifestations may vary from transient arrhythmias to multiorgan dysfunction and death [106]. Reperfusion injury is mediated via reactive oxygen species which damage cellular membranes, stimulate leukocyte activation and endothelial adhesion, and activate the complement. All these pathophysiological changes lead to microcirculatory failure. Hepatic I/R injury affects patient recovery after major surgery and bears a risk of poor postoperative outcome [107]. In liver surgery, ischemic preconditioning (IP) and intermittent clamping are the only established methods to provide protection against tissue damage due to ischemia during inflow occlusion $[98,108]$.

IP is defined as a process in which a short period of ischemia, separated by intermittent reperfusion, renders an organ more tolerant to subsequent episodes of ischemia $[107,109]$. It was initially described for a canine heart by Murry et al. in 1986 [110]. As far as the liver is concerned, the beneficial effect of IP was first demonstrated in a rodent model by Lloris-Carsi et al. [111]. Clavien et al. provided the first clinical evidence of benefit in patients undergoing hemihepatectomy [112]. It leads to improvement of hepatic microcirculation, reduction in tissue apoptosis, and improvement of survival. Experimental data suggest that generation of adenosine, activation of adenosine $\mathrm{A}_{2}$ receptors with subsequent generation of $\mathrm{NO}$ and release of $\mathrm{NO}$ cause vasodilation and prevent the increase in endothelins, thus protecting the liver from reperfusion injury [107]. IP stimulates adenosine receptors on Kupffer cells in nonischemic lobes to produce oxygen radicals, leading to the promotion of liver regeneration after partial hepatectomy [113]. In a clinical study of 61 patients undergoing liver surgery performed by Heizmann et al., the absence of preconditioning was found to be an independent risk factor for postoperative complications [114]. The benefit of ischemia is restricted by old liver [109]. It has been stated that IP might also be less beneficial during extended liver resections, due to hyperperfusion-induced derangement in hepatic microcirculation. Similarly, the effect of preconditioning was lost in patients undergoing tissue loss above 50\% [115]. In small liver remnants of about $30 \%$, it may in fact have detrimental effects. This is because the small remaining tissue suffers from shear stress-associated microvascular injury. Ischemic preconditioning seems to attenuate the apoptotic response of hepatic cells in major hepatectomies performed under SHVE [115]. On the other hand, Azoulay et al. found that IP failed to protect human liver against IR injury after major hepatectomy under continuous vascular occlusion with preservation of caval flow [116]. Other strategies should be used to induce protection in this setting. Combined IP and salvialonic acid-B have been shown to possess synergistically protective effects in rats, mediated through reduction of postischemic oxidative stress, higher ATP levels and reduction in hepatocellular apoptosis [105].

The severity of IR injury is related to the duration of vascular occlusion. The preconditioning effect fades away when the ischemic time is prolonged [108]. In this case, intermittent vascular occlusion, although more complex surgically, seems to be the method of choice. Van Wagensveld et al. demonstrated that prolonged intermittent vascular inflow occlusion in pig liver surgery caused less microcirculation impairment and hepatocellular necrosis compared with continuous occlusion and recommend it when a prolonged period of vascular inflow occlusion is expected [117]. It has been found that when ischemia persists for more than 40 minutes, intermittent vascular occlusion offers better protection of liver cells, demonstrated by lower AST values, lower apoptotic activity and reduced capsase-3 activation [108]. 
In several animal models, pharmacological preconditioning with a volatile anesthetic has been proven to provide protection against ischemic injury. Beck-Schimmer et al. evaluated the effects of sevoflurane preconditioning before liver ischemia and concluded that this particular volatile anesthetic limited the postoperative increase of serum transaminase levels by $261 \mathrm{U} / \mathrm{L}$ for the ALT and by $239 \mathrm{U} / \mathrm{L}$ for the AST. The sevoflurane group had less major complications (such as sepsis, bilioma, bleeding, and infection) than the control (propofol) group. The protective effects were more pronounced in patients with liver steatosis [20]. However, according to Wang et al., propofol also seems to have the ability to protect human hepatic L02 cells from $\mathrm{H}_{2} \mathrm{O}_{2}$-induced apoptosis [118]. Intraportal administration of L-arginine, a precursor of $\mathrm{NO}$, has been recently studied in pigs and appears to reduce cell damage during the early phase of reperfusion, by downregulating capsase- 3 activty and by preserving mitochondrial structure. Clinically, it resulted in a reduction of AST and an increase in bile production [119]. In another animal study, simvastatin $(5 \mathrm{mg} / \mathrm{kg})$ protected the rat liver from I/R injury by regulating the inflammatory response and by improving microvascular flow [120]. Prostaglandins have also been found to have protective effects on I/R-injured livers by inhibiting the generation of reactive oxygen species, preventing leucocyte migration, improving hepatic insulin and lipid metabolism and regulating the production of inflammatory cytokines. They are also essential after hepatectomy because they promote hepatocyte proliferation [121].

Finally, Ramalho et al. reported that angiotensin II type I receptor (AT1R) antagonist increased regeneration in nonsteatotic livers, while in the presence of steatosis both AT1R and AT2R antagonists increased liver regeneration [122].

\section{Conclusions}

Hepatic vascular occlusion techniques require anesthetic expertise. Intolerance to THVE is not unusual and this method should be reserved for patients in need for extensive reconstruction of the inferior vena cava. SHVE has the most favorable intraoperative and postoperative hemodynamic profile. Inflow occlusion techniques, although simple and effective, require specific anesthetic manipulations to reduce liver injury and prevent backflow bleeding.

Every method of hepatic vascular control applied under a carefully selected anesthetic plan can improve the outcome of patients undergoing hepatectomy. The surgeon and anesthesiologist must work together effectively. Anesthetic vigilance along with thorough knowledge of the surgical manipulations promotes team-based health care in the operative room.

\section{References}

[1] J. A. Del Olmo, B. Flor-Lorente, B. Flor-Civera et al., "Risk factors for nonhepatic surgery in patients with cirrhosis," World Journal of Surgery, vol. 27, no. 6, pp. 647-652, 2003.
[2] L. Dagher and K. Moore, "The hepatorenal syndrome," Gut, vol. 49, no. 5, pp. 729-737, 2001.

[3] A. T. Mazzeo, T. Lucanto, and L. B. Santamaria, "Hepatopulmonary syndrome: a concern for the anesthetist? Preoperative evaluation of hypoxemic patients with liver disease," Acta Anaesthesiologica Scandinavica, vol. 48, no. 2, pp. 178-186, 2004.

[4] P. Ginès, M. Guevara, V. Arroyo, and J. Rodés, "Hepatorenal syndrome," The Lancet, vol. 362, no. 9398, pp. 1819-1827, 2003.

[5] F. Saner, "Kidney failure following liver resection," Transplantation Proceedings, vol. 40, no. 4, pp. 1221-1224, 2008.

[6] K. Slankamenac, S. Breitenstein, U. Held, B. Beck-Schimmer, M. A. Puhan, and P. A. Clavien, "Development and validation of a prediction score for postoperative acute renal failure following liver resection," Annals of Surgery, vol. 250, no. 5, pp. 720-727, 2009.

[7] O. Picker, C. Beck, and B. Pannen, "Liver protection in the perioperative setting," Best Practice and Research, vol. 22, no. 1, pp. 209-224, 2008.

[8] E. Delva, Y. Camus, B. Nordlinger et al., "Vascular occlusions for liver resections. Operative management and tolerance to hepatic ischemia: 142 cases," Annals of Surgery, vol. 209, no. 2, pp. 211-218, 1989.

[9] J. Belghiti, R. Noun, R. Malafosse et al., "Continuous versus intermittent portal triad clamping for liver resection: a controlled study," Annals of Surgery, vol. 229, no. 3, pp. 369375, 1999.

[10] N. D. Maynard, D. J. Bihari, R. N. Dalton, R. Beale, M. N. Smithies, and R. C. Mason, "Liver function and splanchnic ischemia in critically ill patients," Chest, vol. 111, no. 1, pp. 180-187, 1997.

[11] C. Ripoll, R. Yotti, J. Bermejo, and R. Bañares, “The heart in liver transplantation," Journal of Hepatology, vol. 54, no. 4, pp. 810-822, 2011.

[12] J. Etisham, M. Altieri, E. Salame et al., "Coronary artery disease in orthotopic liver transplantation: pretransplant assessment and management," Liver Transplantation, vol. 16, pp. 550-557, 2010.

[13] A. Chévalier, "Anesthesia and hepatic resection," Anesthesiology Rounds, vol. 4, pp. 1-6, 2005.

[14] J. R. Ortiz, J. A. Percaz, and F. Carrascosa, "Cisatracurium," Revista Espanola de Anestesiologia y Reanimacion, vol. 45, no. 6, pp. 242-247, 1998.

[15] X. C. Weng, L. Zhou, Y. Y. Fu, S. M. Zhu, H. L. He, and J. Wu, "Dose requirements of continuous infusion of rocuronium and atracurium throughout orthotopic liver transplantation in humans," Journal of Zhejiang University, Science B, vol. 6, no. 9, pp. 869-872, 2005.

[16] I. Redai, J. Emond, and T. Brentjens, "Anesthetic considerations during liver surgery," Surgical Clinics of North America, vol. 84, no. 2, pp. 401-411, 2004.

[17] C. Gatecel, M. R. Losser, and D. Payen, "The postoperative effects of halothane versus isoflurane on hepatic artery and portal vein blood flow in humans," Anesthesia \& Analgesia, vol. 96, no. 3, pp. 740-745, 2003.

[18] A. Hoetzel, S. Geiger, T. Loop et al., "Differential effects of volatile anesthetics on hepatic heme oxygenase- 1 Expression in the rat," Anesthesiology, vol. 97, no. 5, pp. 1318-1321, 2002.

[19] N. Kanaya, M. Nakayama, S. Fujita, and A. Namiki, "Comparison of the effects of sevoflurane, isoflurane and halothane on indocyanine green clearance," British Journal of Anaesthesia, vol. 74, no. 2, pp. 164-167, 1995. 
[20] B. Beck-Schimmer, S. Breitenstein, S. Urech et al., "A randomized controlled trial on pharmacological preconditioning in liver surgery using a volatile anesthetic," Annals of Surgery, vol. 248, no. 6, pp. 909-916, 2008.

[21] D. D. Koblin, "Characteristics and implications of desflurane metabolism and toxicity," Anesthesia \& Analgesia, vol. 75, supplement 4, pp. S10-S16, 1992.

[22] J. S. Ko, M. S. Gwak, S. J. Choi et al., "The effects of desflurane and sevoflurane on hepatic and renal functions after right hepatectomy in living donors," Transplant International, vol. 23, no. 7, pp. 736-744, 2010.

[23] M. Arslan, O. Kurtipek, A. T. Dogan et al., "Comparison of effects of anaesthesia with desflurane and enflurane on liver function," Singapore Medical Journal, vol. 50, no. 1, pp. 7377, 2009.

[24] B. Laviolle, C. Basquin, D. Aguillon et al., "Effect of an anesthesia with propofol compared with desflurane on free radical production and liver function after partial hepatectomy," Fundamental and Clinical Pharmacology. In press.

[25] E. K. Abdalla, R. Noun, and J. Belghiti, "Hepatic vascular occlusion: which technique?" Surgical Clinics of North America, vol. 84, no. 2, pp. 563-585, 2004.

[26] J. Belghiti, "Vascular isolation techniques in liver resection," in Surgery of the Liver and the Biliary Tract, L. M. Blugmart, Ed., pp. 1715-1724, Churchill Livingstone, New York, NY, USA, 2001.

[27] F. Decaillot, D. Cherqui, B. Leroux et al., "Effects of portal triad clamping on hemodynamic conditions during laparoscopic liver resection," British Journal of Anaesthesia, vol. 87, pp. 493-496, 2001.

[28] E. Delva, Y. Camus, C. Paugam, R. Parc, C. Huguet, and A. Lienhart, "Hemodynamic effects of portal triad clamping in humans," Anesthesia \& Analgesia, vol. 66, no. 9, pp. 864-868, 1987.

[29] D. Franco, "Liver surgery has become simpler," European Journal of Anaesthesiology, vol. 19, no. 11, pp. 777-779, 2002.

[30] R. M. Jones, C. E. Moulton, and K. J. Hardy, "Central venous pressure and its effect on blood loss during liver resection," British Journal of Surgery, vol. 85, no. 8, pp. 1058-1060, 1998.

[31] M. Johnson, R. Mannar, and A. V. O. Wu, "Correlation between blood loss and inferior vena caval pressure during liver resection," British Journal of Surgery, vol. 85, no. 2, pp. 188-190, 1998.

[32] P. J. Allen and W. R. Jarnagin, "Current status of hepatic resection," Advances in Surgery, vol. 37, pp. 29-49, 2003.

[33] V. E. Smyrniotis, G. G. Kostopanagiotou, J. C. Contis et al., "Selective hepatic vascular exclusion versus Pringle maneuver in major liver resections: prospective study," World Journal of Surgery, vol. 27, no. 7, pp. 765-769, 2003.

[34] J. A. Melendez, V. Arslan, M. E. Fischer et al., "Perioperative outcomes of major hepatic resections under low central venous pressure anesthesia: blood loss, blood transfusion, and the risk of postoperative renal dysfunction," Journal of the American College of Surgeons, vol. 187, no. 6, pp. 620-625, 1998.

[35] G. Torzilli, M. Makuuchi, K. Inoue et al., "No-mortality liver resection for hepatocellular carcinoma in cirrhotic and noncirrhotic patients: is there a way? A prospective analysis of our approach," Archives of Surgery, vol. 134, no. 9, pp. 984992, 1999.

[36] G. Torzilli, M. Makuuchi, Y. Midorikawa et al., "Liver resection without total vascular exclusion: hazardous or beneficial? An analysis of our experience," Annals of Surgery, vol. 233, no. 2, pp. 167-175, 2001.
[37] J. D. Cunningham, Y. Fong, C. Shriver, J. Melendez, W. L. Marx, and L. H. Blumgart, "One hundred consecutive hepatic resections: blood loss, transfusion, and operative technique," Archives of Surgery, vol. 129, no. 10, pp. 10501056, 1994.

[38] M. Shimoda, Y. Iwasaki, T. Okada, T. Sawada, and K. Kubota, "Protective effect of Sivelestat in a porcine hepatectomy model prepared using an intermittent Pringle method," European Journal of Pharmacology, vol. 587, no. 1-3, pp. 248-252, 2008.

[39] D. Eyraud, O. Richard, D. C. Borie et al., "Hemodynamic and hormonal responses to the sudden interruption of caval flow: insights from a prospective study of hepatic vascular exclsion during major liver resections," Anesthesia \& Analgesia, vol. 95, pp. 1173-1178, 2002.

[40] G. Biancofiore, L. A. H. Critchley, A. Lee et al., "Evaluation of an uncalibrated arterial pulse contour cardiac output monitoring system in cirrhotic patients undergoing liver surgery," British Journal of Anaesthesia, vol. 102, no. 1, pp. 47-54, 2009.

[41] H. Kjekshus, C. Risoe, T. Scholz, and O. A. Smiseth, "Regulation of hepatic vascular volume: contributions from active and passive mechanisms during catecholamine and sodium nitroprusside infusion," Circulation, vol. 96, no. 12, pp. 4415-4423, 1997.

[42] V. Krejci, L. B. Hiltebrand, and G. H. Sigurdsson, "Effects of epinephrine, norepinephrine, and phenylephrine on microcirculatory blood flow in the gastrointestinal tract in sepsis," Critical Care Medicine, vol. 34, no. 5, pp. 1456-1463, 2006.

[43] S. Klinzing, M. Simon, K. Reinhart, D. L. Bredle, and A. Meier-Hellmann, "High-dose vasopressin is not superior to norepinephrine in septic shock," Critical Care Medicine, vol. 31, no. 11, pp. 2646-2650, 2003.

[44] J. Polio, C. C. Sieber, E. Lerner, and R. J. Groszmann, "Cardiovascular hyporesponsiveness to norepinephrine, propranolol and nitroglycerin in portal-hypertensive and aged rats," Hepatology, vol. 18, no. 1, pp. 128-136, 1993.

[45] A. Castro, W. Jimenez, J. Claria et al., "Impaired responsiveness to angiotensin II in experimental cirrhosis: role of nitric oxide," Hepatology, vol. 18, no. 2, pp. 367-372, 1993.

[46] T. H. Swygert, L. C. Roberts, T. R. Valek et al., "Effect of intraoperative low-dose dopamine on renal function in liver transplant recipients," Anesthesiology, vol. 75, no. 4, pp. 571576, 1991.

[47] G. Della Rocca, L. Pompei, M. G. Costa et al., "Fenoldopam mesylate and renal function in patients undergoing liver transplantation: a randomized, controlled pilot trial," Anesthesia \& Analgesia, vol. 99, no. 6, pp. 1604-1609, 2004.

[48] N. Brienza, V. Malcangi, L. Dalfino et al., "A comparison between fenoldopam and low-dose dopamine in early renal dysfunction of critically ill patients," Critical Care Medicine, vol. 34, no. 3, pp. 707-714, 2006.

[49] T. Restuccia, R. Ortega, M. Guevara et al., "Effects of treatment of hepatorenal syndrome before transplantation on posttransplantation outcome. A case-control study," Journal of Hepatology, vol. 40, no. 1, pp. 140-146, 2004.

[50] L. Hannoun, L. Delrivière, P. Gibbs, D. Borie, J. C. Vaillant, and E. Delva, "Major extended hepatic resections in diseased livers using hypothermic protection: preliminary results from the first 12 patients treated with this new technique," Journal of the American College of Surgeons, vol. 183, no. 6, pp. 597-605, 1996.

[51] M. Miyazaki, H. Ito, K. Nakagawa et al., "Aggressive surgical resection for hepatic metastases involving the inferior vena 
cava," American Journal of Surgery, vol. 177, no. 4, pp. 294298, 1999.

[52] M. Cescon, G. Vetrone, G. L. Grazi et al., "Trends in perioperative outcome after hepatic resection: analysis of 1500 consecutive unselected cases over 20 years," Annals of Surgery, vol. 249, no. 6, pp. 995-1002, 2009.

[53] D. Cherqui, B. Malassagne, P. I. Colau, F. Brunetti, N. Rotman, and P. L. Fagniez, "Hepatic vascular exclusion with preservation of the caval flow for liver resections," Annals of Surgery, vol. 230, no. 1, pp. 24-30, 1999.

[54] V. E. Smyrniotis, G. G. Kostopanagiotou, E. L. Gamaletsos et al., "Total versus selective hepatic vascular exclusion in major liver resections," American Journal of Surgery, vol. 183, no. 2, pp. 173-178, 2002.

[55] J. Belghiti, R. Noun, E. Zante, T. Ballet, and A. Sauvanet, "Portal triad clamping or hepatic vascular exclusion for major liver resection: a controlled study," Annals of Surgery, vol. 224, no. 2, pp. 155-161, 1996.

[56] D. Elias, P. Dubé, S. Bonvalot, B. Debanne, B. Plaud, and P. Lasser, "Intermittent complete vascular exclusion of the liver during hepatectomy: technique and indications," HepatoGastroenterology, vol. 45, no. 20, pp. 389-395, 1998.

[57] V. Smyrniotis, G. Kostopanagiotou, K. Theodoraki, D. Tsantoulas, and J. C. Contis, "The role of central venous pressure and type of vascular control in blood loss during major liver resections," American Journal of Surgery, vol. 187, no. 3, pp. 398-402, 2004.

[58] W. Zhou, A. Li, Z. Pan et al., "Selective hepatic vascular exclusion and Pringle maneuver: a comparative study in liver resection," European Journal of Surgical Oncology, vol. 34, no. 1, pp. 49-54, 2008.

[59] S. J. Moug, D. Smith, E. Leen, W. J. Angerson, and P. G. Horgan, "Selective continuous vascular occlusion and perioperative fluid restriction in partial hepatectomy. Outcomes in 101 consecutive patients," European Journal of Surgical Oncology, vol. 33, no. 8, pp. 1036-1041, 2007.

[60] M. A. Mirski, A. V. Lele, L. Fitzsimmons, and T. J. K. Toung, "Diagnosis and treatment of vascular air embolism," Anesthesiology, vol. 106, no. 1, pp. 164-177, 2007.

[61] S. Y. Lee, B. I. W. Choi, J. S. Kim, and K. S. Park, "Paradoxical air embolism during hepatic resection," British Journal of Anaesthesia, vol. 88, no. 1, pp. 136-138, 2002.

[62] Z. M. Hu, W. D. Wu, C. W. Zhang, Y. H. Zhang, Z. Y. Ye, and D. J. Zhao, "Selective exclusion of hepatic outflow and inflow in hepatectomy for huge hepatic tumor," Zhonghua Zhong Liu Za Zhi, vol. 30, no. 8, pp. 620-622, 2008.

[63] Z. Y. Pan, Y. Yang, W. P. Zhou, A. J. Li, S. Y. Fu, and M. C. Wu, "Clinical application of hepatic venous occlusion for hepatectomy," Chinese Medical Journal, vol. 121, no. 9, pp. 806-810, 2008.

[64] W. Zhou, A. Li, Z. Pan et al., "Selective hepatic vascular exclusion and Pringle maneuver: a comparative study in liver resection," European Journal of Surgical Oncology, vol. 34, no. 1, pp. 49-54, 2008.

[65] T. S. Helling, B. Blondeau, and B. J. Wittek, "Perioperative factors and outcome associated with massive blood loss during major liver resections," $H P B$, vol. 6, no. 3, pp. 181$185,2004$.

[66] T. J. K. Toung, M. I. Rossberg, and G. M. Hutchins, "Volume of air in a lethal venous air embolism," Anesthesiology, vol. 94, no. 2, pp. 360-361, 2001.

[67] H. S. Martland, "Air embolism. Fatal air embolism due to powder insufflators used in gynecological treatments," The American Journal of Surgery, vol. 68, no. 2, pp. 164-169, 1945.
[68] R. A. Jaffe, L. C. Siegel, I. Schnittger, J. W. Propst, and J. G. Brock-Utne, "Epidural air injection assessed by transesophageal echocardiography," Regional Anesthesia, vol. 20, no. 2, pp. 152-155, 1995.

[69] H. Furuya, T. Suzuki, and F. Okumura, "Detection of air embolism by transesophageal echocardiography," Anesthesiology, vol. 58, no. 2, pp. 124-129, 1983.

[70] J. L. Chang, M. S. Albin, L. Bunegin, and T. K. Hung, "Analysis and comparison of venous air embolism detection methods," Neurosurgery, vol. 7, no. 2, pp. 135-141, 1980.

[71] G. Thiéry, F. Le Corre, P. Kirstetter, A. Sauvanett, J. Belghiti, and J. Marty, "Paradoxical air embolism during orthoptic liver transplantation: diagnosis by transoesophageal echocardiography," European Journal of Anaesthesiology, vol. 16, no. 5, pp. 342-345, 1999.

[72] H. Bismuth, D. Castaing, and O. J. Garden, "Major hepatic resection under total vascular exclusion," Annals of Surgery, vol. 210, no. 1, pp. 13-19, 1989.

[73] Y. Hatano, M. Murakawa, H. Segawa, Y. Nishida, and K. Mori, "Venous air embolism during hepatic resection," Anesthesiology, vol. 73, no. 6, pp. 1282-1285, 1990.

[74] V. Melhorn, E. J. Burke, and B. D. Butler, "Body position does not affect the hemodynamic response to venous air embolism in dogs," Anesthesia \& Analgesia, vol. 79, pp. 734-739, 1994.

[75] C. A. Moulton, A. K. K. Chui, D. Mann, P. B. S. Lai, P. T. Chui, and W. Y. Lau, "Does patient position during liver surgery influence the risk of venous air embolism?" American Journal of Surgery, vol. 181, no. 4, pp. 366-367, 2001.

[76] M. Booke, H. G. Bone, H. Van Aken, F. Hinder, U. Jahn, and J. Meyer, "Venous paradoxical air embolism," Anaesthesist, vol. 48, no. 4, pp. 236-241, 1999.

[77] G. G. Jamieson, L. Corbel, J. P. Campion, and B. Launois, "Major liver resection without a blood transfusion: is it a realistic objective?" Surgery, vol. 112, no. 1, pp. 32-36, 1992.

[78] S. C. Katz, J. Shia, K. H. Liau et al., "Operative blood loss independently predicts recurrence and survival after resection of hepatocellular carcinoma," Annals of Surgery, vol. 249, no. 4, pp. 617-623, 2009.

[79] J. L. Carson, H. Noveck, J. A. Berlin, and S. A. Gould, "Mortality and morbidity in patients with very low postoperative $\mathrm{Hb}$ levels who decline blood transfusion," Transfusion, vol. 42, no. 7, pp. 812-818, 2002.

[80] J. L. Carson, S. Hill, P. Carless, P. Hébert, and D. Henry, "Transfusion Triggers: a systematic review of the literature," Transfusion Medicine Reviews, vol. 16, no. 3, pp. 187-199, 2002.

[81] J. P. Arnoletti and J. Brodsky, "Reduction of transfusion requirements during major hepatic resection for metastatic disease," Surgery, vol. 125, no. 2, pp. 166-171, 1999.

[82] E. Dixon, C. M. Vollmer, O. F. Bathe, and F. Sutherland, "Vascular occlusion to decrease blood loss during hepatic resection," American Journal of Surgery, vol. 190, no. 1, pp. 75-86, 2005.

[83] K. Man, S. T. Fan, I. O. L. Ng, C. M. Lo, C. L. Liu, and J. Wong, "Prospective evaluation of pringle maneuver in hepatectomy for liver tumors by a randomized study," Annals of Surgery, vol. 226, no. 6, pp. 704-713, 1997.

[84] K. Man, C. M. Lo, C. L. Liu et al., "Effects of the intermittent Pringle manoeuvre on hepatic gene expression and ultrastructure in a randomized clinical study," British Journal of Surgery, vol. 90, no. 2, pp. 183-189, 2003.

[85] K. Man, S. T. Fan, I. O. L. Ng et al., "Tolerance of the liver to intermittent Pringle maneuver in hepatectomy for liver 
tumors," Archives of Surgery, vol. 134, no. 5, pp. 533-539, 1999.

[86] M. Makuuchi, T. Mori, P. Guneven et al., "Safety of Hemihepatic vascular control technique for hepatic resection," The American Journal of Surgery, vol. 164, pp. 155-158, 1987.

[87] W. D. Wang, L. J. Liang, X. Q. Huang, and X. Y. Yin, "Low central venous pressure reduces blood loss in hepatectomy," World Journal of Gastroenterology, vol. 12, no. 6, pp. 935-939, 2006.

[88] A. Y. C. Wong, M. G. Irwin, T. W. C. Hui, S. K. Y. Fung, S. T. Fan, and E. S. K. Ma, "Desmopressin does not decrease blood loss and transfusion requirements in patients undergoing hepatectomy," Canadian Journal of Anesthesia, vol. 50, no. 1, pp. 14-20, 2003.

[89] J. P. A. Lodge, S. Jonas, E. Oussoultzoglou et al., "Recombinant coagulation factor VIIa in major liver resection: a randomized, placebo-controlled, double-blind clinical trial," Anesthesiology, vol. 102, no. 2, pp. 269-275, 2005.

[90] C. Lentschner, K. Roche, and Y. Ozier, "A review of aprotinin in orthotopic liver transplantation: can its harmful effects offset its beneficial effects?" Anesthesia \& Analgesia, vol. 100, pp. 1248-1255, 2005.

[91] I. T. A. Pereboom, M. T. De Boer, R. J. Porte, and I. Q. Molenaar, "Aprotinin and nafamostat mesilate in liver surgery: effect on blood loss," Digestive Surgery, vol. 24, no. 4, pp. 282-287, 2007.

[92] C. C. Wu, W. M. Ho, S. B. Cheng et al., "Perioperative parenteral tranexamic acid in liver tumor resection: a prospective randomized trial toward "blood transfusion"free hepatectomy," Annals of Surgery, vol. 243, no. 2, pp. 173180, 2006.

[93] D. A. Henry, P. A. Carless, A. J. Moxey et al., "Anti-fibrinolytic use for minimising perioperative allogeneic blood transfusion," Cochrane Database of Systematic Reviews, no. 4, Article ID CD001886, 2007.

[94] D. R. Spahn and M. Casutt, "Eliminating blood transfusions: new aspects and perspectives," Anesthesiology, vol. 93, no. 1, pp. 242-255, 2000.

[95] D. R. Spahn and R. Kocian, "Artificial $\mathrm{O}_{2}$ carriers: status in 2005," Current Pharmaceutical Design, vol. 11, no. 31, pp. 4099-4114, 2005.

[96] D. R. Spahn and R. Kocian, "The place of artificial oxygen carriers in reducing allogeneic blood transfusions and augmenting tissue oxygenation," Canadian Journal of Anesthesia, vol. 50, supplement 6, pp. S41-S47, 2003.

[97] C. Pulitanò, M. Arru, L. Bellio, S. Rossini, G. Ferla, and L. Aldrighetti, "A risk score for predicting perioperative blood transfusion in liver surgery," British Journal of Surgery, vol. 94, no. 7, pp. 860-865, 2007.

[98] C. C. Wang, S. G. Iyer, J. K. Low et al., "Perioperative factors affecting long-term outcomes of 473 consecutive patients undergoing hepatectomy for hepatocellular carcinoma," Annals of Surgical Oncology, vol. 16, no. 7, pp. 1832-1842, 2009.

[99] N. Shinozuka, I. Koyama, T. Arai et al., "Autologous blood transfusion in patients with hepatocellular carcinoma undergoing hepatectomy," American Journal of Surgery, vol. 179, no. 1, pp. $42-45,2000$.

[100] P. M. Kopko and P. V. Holland, "Transfusion-related acute lung injury," British Journal of Haematology, vol. 105, no. 2, pp. 322-329, 1999.

[101] A. B. Benson, J. R. Burton, G. L. Austin et al., "Differential effects of plasma and red blood cell transfusions on acute lung injury and infection risk following liver transplantation," Liver Transplantation, vol. 17, no. 2, pp. 149-158, 2011.

[102] H. Nakazawa, H. Ohnishi, H. Okazaki et al., "Impact of fresh-frozen plasma from male-only donors versus mixedsex donors on postoperative respiratory function in surgical patients: a prospective case-controlled study," Transfusion, vol. 49, no. 11, pp. 2434-2441, 2009.

[103] M. Palfi, S. Berg, J. Ernerudh, and G. Berlin, "A randomized controlled trial of transfusion-related acute lung injury: is plasma from multiparous blood donors dangerous?" Transfusion, vol. 41, no. 3, pp. 317-322, 2001.

[104] A. F. Eder, R. Herron, A. Strupp et al., "Transfusion-related acute lung injury surveillance (2003-2005) and the potential impact of the selective use of plasma from male donors in the American Red Cross," Transfusion, vol. 47, no. 4, pp. 599-607, 2007.

[105] R. Kong, Y. Gao, B. Sun et al., "The stategy of combined ischemia preconditioning and salvianolic acid-B pretreatment to prevent hepatic ischemia-reperfusion injury in rats," Digestive Diseases and Sciences, vol. 54, no. 12, pp. 2568-2576, 2009.

[106] C. D. Collard and S. Gelman, "Pathophysiology, clinical manifestations, and prevention of ischemia-reperfusion injury," Anesthesiology, vol. 94, no. 6, pp. 1133-1138, 2001.

[107] C. Eipel, M. Glanemann, A. K. Nuessler, M. D. Menger, P. Neuhaus, and B. Vollmar, "Ischemic preconditioning impairs liver regeneration in extended reduced-size livers," Annals of Surgery, vol. 241, no. 3, pp. 477-484, 2005.

[108] V. Smyrniotis, K. Theodoraki, N. Arkadopoulos et al., "Ischemic preconditioning versus intermittent vascular occlusion in liver resections performed under selective vascular exclusion: a prospective randomized study," American Journal of Surgery, vol. 192, no. 5, pp. 669-674, 2006.

[109] S. Suzuki, K. Inaba, and H. Konno, "Ischemic preconditioning in hepatic ischemia and reperfusion," Current Opinion in Organ Transplantation, vol. 13, no. 2, pp. 142-147, 2008.

[110] C. E. Murry, R. B. Jennings, and K. A. Reimer, "Preconditioning with ischemia: a delay of lethal cell injury in ischemic myocardium," Circulation, vol. 74, no. 5, pp. 1124-1136, 1986.

[111] J. M. Lloris-Carsi, D. Cejalvo, L. H. Toledo-Pereyra, M. A. Calvo, and S. Suzuki, "Preconditioning: effect upon lesion modulation in warm liver ischemia," Transplantation Proceedings, vol. 25, no. 6, pp. 3303-3304, 1993.

[112] P. A. Clavien, S. Yadav, D. Sindram, and R. C. Bentley, "Protective effects of ischemic preconditioning for liver resection performed under inflow occlusion in humans," Annals of Surgery, vol. 232, no. 2, pp. 155-162, 2000.

[113] M. Arai, K. Tejima, H. Ikeda et al., "Ischemic preconditioning in liver pathophysiology," Journal of Gastroenterology and Hepatology, vol. 13, pp. 657-670, 2007.

[114] O. Heizmann, F. Loehe, A. Volk, and R. J. Schauer, "Ischemic preconditioning improves postoperative outcome after liver resections: a randomized controlled study," European Journal of Medical Research, vol. 13, no. 2, pp. 79-86, 2008.

[115] N. Arkadopoulos, G. Kostopanagiotou, K. Theodoraki et al., "Ischemic preconditioning confers antiapoptotic protection during major hepatectomies performed under combined inflow and outflow exclusion of the liver. A randomized clinical trial," World Journal of Surgery, vol. 33, no. 9, pp. 1909-1915, 2009.

[116] D. Azoulay, M. Del Gaudio, P. Andreani et al., "Effects of 10 minutes of ischemic preconditioning of the cadaveric liver on 
the graft's preservation and function: the Ying and the Yang," Annals of Surgery, vol. 242, no. 1, pp. 133-139, 2005.

[117] B. A. Van Wagensveld, T. M. Van Gulik, H. C. Gelderblom et al., "Prolonged continuous or intermittent vascular inflow occlusion during hemihepatectomy in pigs," Annals of Surgery, vol. 229, no. 3, pp. 376-384, 1999.

[118] H. Wang, Z. Xue, Q. Wang et al., "Propofol protects hepatic L02 cells from hydrogen peroxide-induced apoptosis via activation of extracellular signal-regulated kinases pathway," Anesthesia \& Analgesia, vol. 107, pp. 534-540, 2008.

[119] R. O. Giovanardi, E. L. Rhoden, C. T. Cerski, M. Salvador, and A. N. Kalil, "Pharmacological preconditioning using intraportal infusion of L-arginine protects against hepatic ischemia reperfusion injury," Journal of Surgical Research, vol. 155, no. 2, pp. 244-253, 2009.

[120] I. R. Lai, K. J. Chang, H. W. Tsai, and C. F. Chen, "Pharmacological preconditioning with simvastatin protects liver from ischemia-reperfusion injury by heme oxygenase-1 induction," Transplantation, vol. 85, no. 5, pp. 732-738, 2008.

[121] M. A. Hossain, H. Wakabayashi, K. Izuishi, K. Okano, S. Yachida, and H. Maeta, "The role of prostaglandins in liver ischemia-reperfusion injury," Current Pharmaceutical Design, vol. 12, no. 23, pp. 2935-2951, 2006.

[122] F. S. Ramalho, I. Alfany-Fernandez, A. Casillas-Ramirez et al., "Are angiotensin II receptor antagonists useful strategies in steatotic and nonsteatotic livers in conditions of partial hepatectomy under ischemia-reperfusion?" Journal of Pharmacology and Experimental Therapeutics, vol. 329, no. 1, pp. 130-140, 2009.

[123] V. Smyrniotis, C. Farantos, G. Kostopanagiotou, and N. Arkadopoulos, "Vascular control during hepatectomy: review of methods and results," World Journal of Surgery, vol. 29, no. 11, pp. 1384-1396, 2005.

[124] J. Figueras, L. Llado, D. Ruiz et al., "Complete versus selective portal triad clamping for minor liver resections: a prospective randomized trial," Annals of Surgery, vol. 241, no. 4, pp. 582590, 2005.

[125] G. Nuzzo, F. Giuliante, I. Giovannini, M. Vellone, G. De Cosmo, and G. Capelli, "Liver resections with or without pedicle clamping," American Journal of Surgery, vol. 181, no. 3, pp. 238-246, 2001.

[126] R. Omar Giovanardi, H. Joäo Giovanardi, M. Bozetti, R. Garcia, and L. Pereira Lima, "Intermittent total pedicular clamping in hepatic resections in non-cirrhotic patients," Hepato-Gastroenterology, vol. 49, no. 45, pp. 764-769, 2002.

[127] S. Y. Fu, E. C. H. Lai, A. J. Li et al., "Liver resection with selective hepatic vascular exclusion: a cohort study," Annals of Surgery, vol. 249, no. 4, pp. 624-627, 2009.

[128] Y. Ishizaki, J. Yoshimoto, H. Sugo, K. Miwa, and S. Kawasaki, "Hepatectomy using traditional Péan clamp-crushing technique under intermittent Pringle maneuver," American Journal of Surgery, vol. 196, no. 3, pp. 353-357, 2008. 


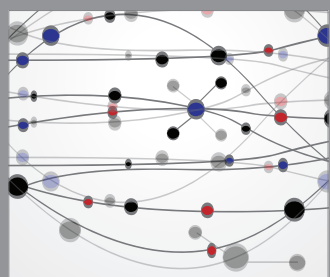

The Scientific World Journal
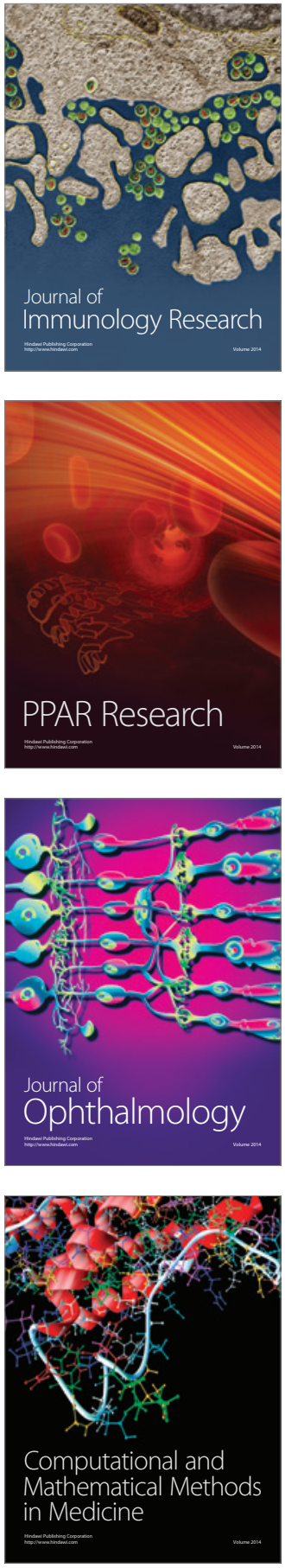

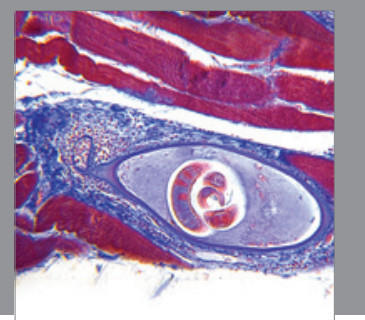

Gastroenterology

Research and Practice
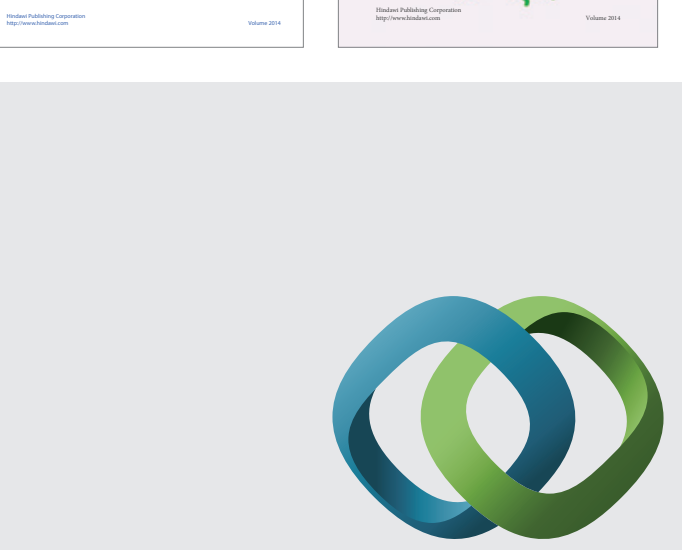

\section{Hindawi}

Submit your manuscripts at

http://www.hindawi.com
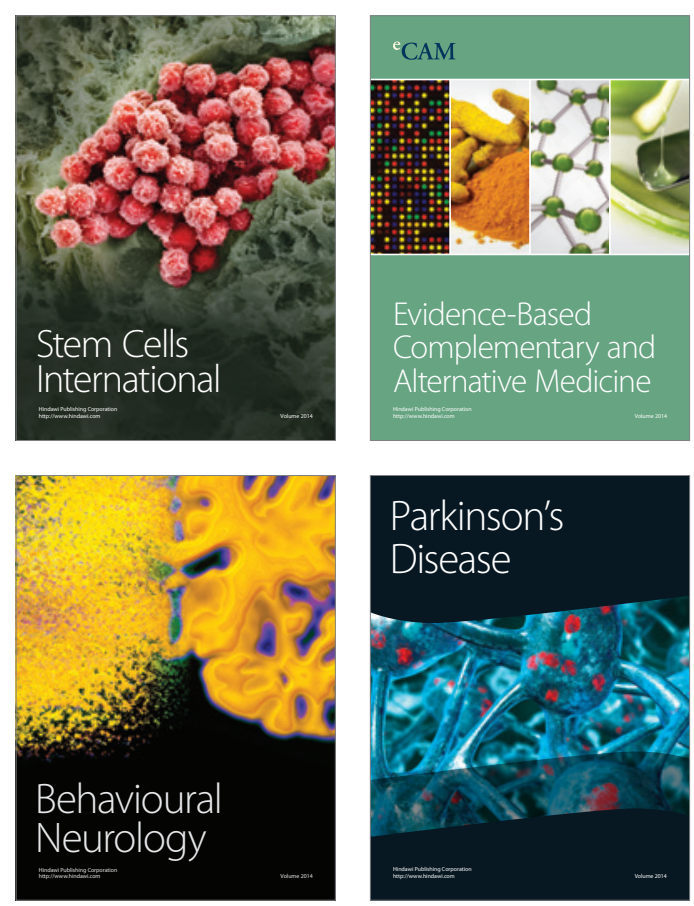

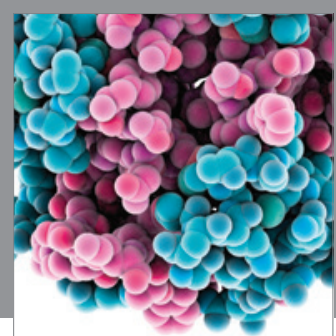

Journal of
Diabetes Research

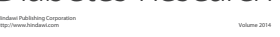

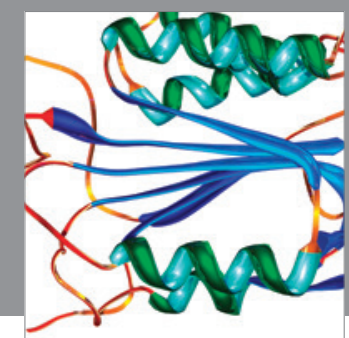

Disease Markers
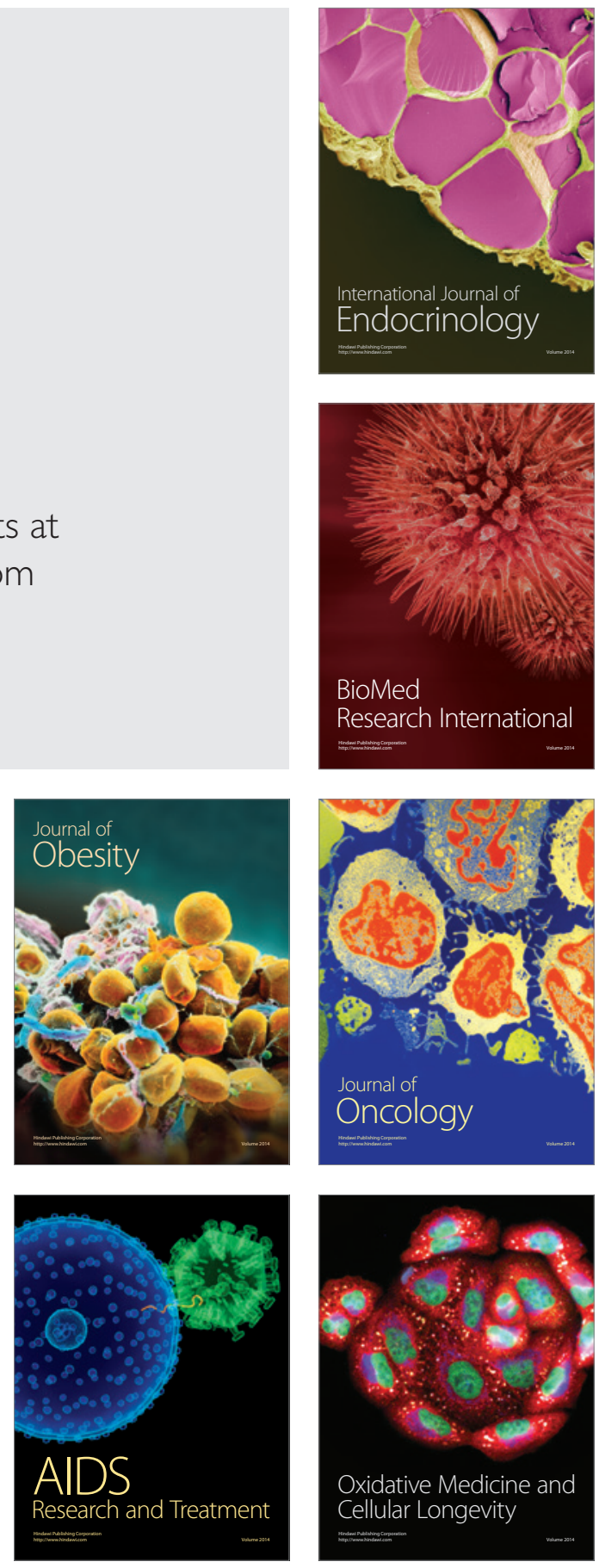